\title{
Multimodal Imaging of Pathologic Response to Chemoradiation in Esophageal Cancer
}

\author{
Penny Fang, M.D. ${ }^{\dagger}$, Benjamin C. Musall, M.S. ${ }^{\dagger}$, Jong Bum Son, Ph.D., Amy C. Moreno, M.D., \\ Brian P. Hobbs, Ph.D., Brett W. Carter, M.D., Bryan M. Fellman, M.S., Osama Mawlawi, \\ Ph.D., Jingfei Ma, Ph.D., and Steven H. Lin, M.D., Ph.D. \\ Departments of Radiation Oncology (P.F., A.C.M., S.H.L.), Imaging Physics (B.C.M., J.M., J.B.S., \\ O.M.), Radiology (B.W.C.), and Biostatistics (B.P.H., B.M.F.), The University of Texas MD \\ Anderson Cancer Center, 1515 Holcombe Boulevard Houston, TX 77030
}

\section{Abstract}

Purpose-To examine the value of early changes in quantitative diffusion-weighted imaging (DWI) and ${ }^{18}$ F-deoxyglucose positron emission tomography/computed tomography (FDG$\mathrm{PET} / \mathrm{CT}$ ) for discriminating complete pathologic response (pCR) to chemoradiation (CRT) in esophageal cancer.

\begin{abstract}
Methods-Twenty esophageal cancer patients treated with chemoradiation followed by surgery were prospectively enrolled. Patients underwent MRI and FDG-PET/CT scans at baseline (BL), interim (IM, 2 weeks after CRT start), and first follow-up (FU). Based on pathologic findings at surgery, patients were categorized into tumor regression groups (TRG1, TRG2, and TRG3+). Distributions of summary statistics in apparent diffusion coefficient (ADC) and FDG-PET at BL and relative change at IM and FU scans were compared between pCR/TRG1 and non-pCR/TRG2+ groups and across readers. Receiver operating characteristics (ROCs) were evaluated for summary measures to characterize discrimination of pCR from non-pCR.
\end{abstract}

Results-Relative changes in tumor volume $\mathrm{ADC}(\triangle \mathrm{ADC})$ mean, $25^{\text {th }}$ and $10^{\text {th }}$ percentiles were able to completely discriminate $(\mathrm{AUC}=1, \mathrm{p}<0.0011$ ) between $\mathrm{pCR}$ and non-pCR (thresholds = $27.7 \%, 29.2 \%$, and $32.1 \%$, respectively) and were found to have high inter-reader reliability ( $95 \%$ limits of agreement of 1.001, 0.944 and 0.940 , respectively). Relative change in total lesion glycolysis (TLG) from BL to IM was significantly different among pCR and non-pCR groups $(\mathrm{p}=0.0117)$ and yielded AUC of 0.947 (95\% CI: 0.8505-1.043). An optimal threshold of 59\% decrease in TLG provided optimal sensitivity (specificity) of 1.000 (0.867). Changes in ADC summary measures were negatively correlated with that of TLG (Spearman, $-0.495, \mathrm{p}=0.027$ ).

Corresponding Author: Steven H. Lin, MD, PhD, Unit 1422, The University of Texas MD Anderson Cancer Center, 1515 Holcombe Boulevard, Houston, TX, 77030. Phone: (713) 563-8490; Fax: (713) 563-2331; shlin@ mdanderson.org.

${ }^{\dagger}$ Co-first Authors, authors contributed equally.

Publisher's Disclaimer: This is a PDF file of an unedited manuscript that has been accepted for publication. As a service to our customers we are providing this early version of the manuscript. The manuscript will undergo copyediting, typesetting, and review of the resulting proof before it is published in its final citable form. Please note that during the production process errors may be discovered which could affect the content, and all legal disclaimers that apply to the journal pertain.

Conflicts of Interest Notification: SHL receives research funding from Elekta Inc., STCube Pharmaceuticals, Hitachi Chemicals, Peregrine Pharmaceuticals, and honorarium from AstraZeneca, however none are in conflict with the research in question. BPH reports a consultantship with Ignyta, Inc. that is unrelated to the research in this study. 
Conclusion-Quantitative volume $\triangle \mathrm{ADC}$ and TLG during treatment may serve as early imaging biomarkers for discriminating pathologic response to chemoradiation in esophageal cancer.

Validation of this data in larger prospective multicenter studies is essential.

\section{Keywords}

Esophageal cancer; diffusion weighted imaging; apparent diffusion coefficient; positron emission tomography; pathologic response; chemoradiation; early response biomarker

\section{Introduction}

Selection of appropriate patients for a wait-and-see approach after chemoradiation (CRT) for esophageal cancer is predicated on identifying biomarkers of early treatment response, enabling identification of patients most likely to have a pathologic complete response (pCR) and derive the least benefit from additional surgery (1-4). Conventional imaging and assessment are not reliable in gauging treatment response during CRT $(5,6)$. Therefore, with current imaging and assessment techniques alone, typically consisting of baseline and serial follow-up imaging (CT or PET) with endoscopy (7), treatment de-escalation or escalation based on tumor response is still unjustified.

Diffusion-weighted imaging (DWI) is a functional MRI technique that enables detection of Brownian motion of water protons in tissues and a quantitative measure of tissue microenvironment $(8,9)$. DWI is a promising imaging modality to assess treatment response in rectal (10-14) and esophageal cancer (15). The apparent diffusion coefficient (ADC) can be calculated from DWI series of different b-values to remove underlying T2-dependence of signals. Additionally, quantitative ${ }^{18} \mathrm{~F}$-deoxyglucose positron emission tomography/ computed tomography (FDG-PET/CT) is indicative of changes in tumor metabolism and could be complementary in discriminating treatment response $(11,14,16-18)$.

The primary objective of this study was to evaluate the discriminatory value of early DWI and FDG-PET/CT for pathologic response during neoadjuvant CRT in patients with esophageal cancer.

\section{Materials and Methods}

\section{Patients and Treatment}

Patients were enrolled on a single institution, institutional review board-approved prospective study after providing written informed consent. Only potentially resectable esophageal cancer patients were enrolled, and all were treated with neoadjuvant CRT and surgery. Chemotherapy typically consisted of 5-fluorouracil and docetaxel. Radiation dose was 50.4Gray in 1.8Gy daily fractions to the planning target volume. Details regarding simulation and treatment planning are presented in Supplementary Methods.

\section{Imaging and Pathologic Assessment}

MRI and FDG-PET/CT scans were acquired at baseline (BL), two weeks after start of CRT (interim, IM), and 4-6 weeks after treatment (FU). Patients were categorized into three 
tumor regression groups (TRGs) based on pathological findings at surgery: TRG1 if 0\% viable tumor cells/pCR in the primary tumor and lymph nodes, TRG2 if $>0 \%$ but $<10 \%$ viable tumor cells, or TRG3+ if $>10 \%$ viable tumor cells (19).

Tumor delineation methods, DWI and FDG-PET/CT protocols are delineated in Supplementary Methods. From contoured tumor volumes, a total of 11 ADC summary measures were calculated: Min, Max, Mean, standard deviation, skewness, kurtosis, 10th, 25th, 50th (median), 75th, and 90th percentiles.

To investigate the inter-reader reliability of measurements, DWI studies were contoured in randomized order using both volume and slice contouring techniques by five separate readers.

\section{Statistical Analysis}

Distributions of summary measures at BL and relative change at IM and FU scans were compared between pCR (TRG1) and non-pCR (TRG2+) using Mann-Whitney (MW) test. For ADC summary measures, inter-feature dependence was assessed using Spearman-rank correlation. Receiver operating characteristics (ROCs) were evaluated for top summary measures for discrimination of pCR from non-pCR. Detailed statistical methods are presented in Supplementary Methods.

\section{Results}

Table 1 depicts detailed patient and tumor characteristics. All 20 patients enrolled were male and $17(85 \%)$ had distal adenocarcinomas. There were no significant differences in clinical baseline characteristics between pCR and non-pCR outcomes. After chemoradiation, 5(25\%) patients had pCR/TRG1, 9(45\%) TRG2, and 6(30\%) TRG3+.

Changes in ADC parameters from BL to IM scans, but not from BL to FU scans discriminated pCR from non-pCR. Assessment of changes in ADC parameters ( $\triangle \mathrm{ADC}$ ) with treatment identified more than 5 summary measures as discriminant of pCR (Table 2). Volume ADC mean was the most significant discriminant measure $(p=0.0011$, Fig 2a). On ROC analysis, the relative change of volume $\mathrm{ADC}$ mean from BL to IM yielded $\mathrm{AUC}=1$ in classifying patients as pCR and non-pCR with a threshold of $28 \%$. In contrast, ADC summary measures from BL (Table 3 ) to FU scans were not significantly different between pCR and non-pCR groups.

Furthermore, measurements of relative changes (BL to IM) of volume ADC summary measures were highly reproducible among readers (Supplementary Table 2). Minimum AUC for discriminating $\mathrm{pCR}$ vs. non-pCR across the five readers using ADC $25^{\text {th }}$ percentile, ADC mean, and ADC $10^{\text {th }}$ percentile measures was $0.987,0.973$ and 0.960. However, the ADC mean from the slice contouring method yielded AUCs $<0.900$ for all readers.

Considering relative changes in PET parameters from BL to IM scans, patients with pCR had significantly greater decreases in TLG $(\mathrm{p}=0.0138)$ than TRG2+ (Table 4). Change in TLG at the IM scan yielded AUC of 0.947 (95\% CI: 0.8505 to 1.043). Youden's optimal sensitivity (specificity) were 1.000 (0.867) for change in TLG at the IM scan (Fig 2b). 
Changes in $\mathrm{SUV}_{\text {max }}, \mathrm{SUV}_{\text {mean }}$ from BL to IM and changes in $\mathrm{SUV}_{\text {max }}, \mathrm{SUV}_{\text {mean }}$, TLG, and MTV from BL to FU were not associated with pathologic response. Change in TLG was negatively correlated with early change in volume ADC mean (Spearman, $-0.495, \mathrm{p}=0.027$ ).

\section{Discussion}

This prospective study evaluated the discriminative value of early changes on DWI and FDG-PET/CT in differentiating pathologic response in esophageal patients treated with chemoradiation followed by surgery. The change in ADC (mean ADC, $10^{\text {th }}$ or $25^{\text {th }}$ percentile, etc) after the first two weeks of CRT, which is not currently part of standard imaging evaluation, was highly discriminant of $\mathrm{pCR}$ at the time of surgery. A change in mean ADC of 28 discriminated pCR with a sensitivity and NPV of 100\%. On FDG$\mathrm{PET} / \mathrm{CT}$, early change in TLG was also associated with pCR, and a 59\% decrease in TLG discriminated pCR with optimal sensitivity (specificity) of 1.000 (0.867). This study provides encouraging results for the potential value of interim multimodal imaging in early discrimination of patients likely to have a pCR to neoadjuvant therapy.

Our results are consistent with findings from a previous study exploring the role of DWI in discriminating pathologic response (15). Van Rossum et al. found that in 20 patients undergoing CRT before surgery, a change in median tumor ADC of $29 \%$ discriminated residual cancer with a sensitivity (specificity) of $100 \%$ (75\%) (15). The threshold change in mean tumor ADC identified in that study was similar despite differences in scanner platforms (3.0 vs. $1.5 \mathrm{~T}, \mathrm{GE}$ vs. Philips). Li et al. investigated the discriminatory value of baseline and follow-up ADC for pathologic response, finding that the follow-up ADC and change in ADC from baseline to follow-up were significantly higher in responders (20). In comparison, our study did not find that baseline or follow-up ADC values were associated with pCR. Li et al. used ADC parameters from a $2 \mathrm{D}$ region of interest on a single axial slice whereas we delineated a 3D volume of interest, which could explain the difference in findings.

Furthermore, we sought to optimize the method by which ADC measurements are performed. We compared slice to volume delineation methods and found that change in ADC mean based on single-slice contours was not discriminant of PCR with the same sensitivity/specificity as volumetric delineation. In addition, inter-reader agreement on $2 \mathrm{D}$ slice contours was inferior to that of volume-based contours.

With respect to FDG-PET/CT imaging, we identified early change in TLG, a proxy measure for overall tumor burden, as significantly discriminant of $\mathrm{pCR}$ in contrast to a prior study which did not identify any discriminators of pCR on interim PET (21).

A limitation of this study is the small sample size, thus, the results of this study are hypothesis generating. The optimal threshold value of change in ADC and TLG in discriminating pCR may need further refinement. Secondly, a minority of PET/CT scans were performed at an outside institution, which may have introduced variability in scan technique. Thirdly, all the patients enrolled were men, which potentially limits the generalizability of the study. 
In conclusion, quantitative ADC changes from DWI and TLG changes from FDG-PET/CT from baseline to interim scans may enable discrimination of complete pathologic response to chemoradiation in esophageal cancer. Multimodal imaging to validate these approaches in a larger cohort is warranted.

\section{Supplementary Material}

Refer to Web version on PubMed Central for supplementary material.

\section{Acknowledgments}

Funding: This research was partially funded by Elekta Inc. and The MD Anderson Cancer Center R. Lee Clark Fellowship. This work was generously funded in part by the National Institutes of Health / National Cancer Institute Cancer Center Support Grant P30CA016672.

Acknowledgements: None

\section{References}

1. Maas M, Beets-Tan RGH, Lambregts DMJ, Lammering G, Nelemans PJ, Engelen SME, et al. Waitand-see policy for clinical complete responders after chemoradiation for rectal cancer. J Clin Oncol Off J Am Soc Clin Oncol. 2011 Dec 10; 29(35):4633-40.

2. Swisher SG, Moughan J, Komaki RU, Ajani JA, Wu TT, Hofstetter WL, et al. Final Results of NRG Oncology RTOG 0246: An Organ-Preserving Selective Resection Strategy in Esophageal Cancer Patients Treated with Definitive Chemoradiation. J Thorac Oncol Off Publ Int Assoc Study Lung Cancer. 2016 Oct 8.

3. Bedenne L, Michel P, Bouché O, Milan C, Mariette C, Conroy T, et al. Chemoradiation followed by surgery compared with chemoradiation alone in squamous cancer of the esophagus: FFCD 9102. J Clin Oncol Off J Am Soc Clin Oncol. 2007 Apr 1; 25(10):1160-8.

4. Stahl M, Stuschke M, Lehmann N, Meyer H-J, Walz MK, Seeber S, et al. Chemoradiation with and without surgery in patients with locally advanced squamous cell carcinoma of the esophagus. J Clin Oncol Off J Am Soc Clin Oncol. 2005 Apr 1; 23(10):2310-7.

5. Schneider PM, Metzger R, Schaefer H, Baumgarten F, Vallbohmer D, Brabender J, et al. Response evaluation by endoscopy, rebiopsy, and endoscopic ultrasound does not accurately predict histopathologic regression after neoadjuvant chemoradiation for esophageal cancer. Ann Surg. 2008 Dec; 248(6):902-8. [PubMed: 19092334]

6. Westerterp M, van Westreenen HL, Reitsma JB, Hoekstra OS, Stoker J, Fockens P, et al. Esophageal cancer: CT, endoscopic US, FDG PET for assessment of response to neoadjuvant therapy-systematic review. Radiology. 2005 Sep; 236(3):841-51. [PubMed: 16118165]

7. NCCN Clinical Practice Guidelines in Oncology. Version 2.2016. [Internet]. National Comprehensive Cancer Network; 2016. Available from: www.nccn.org

8. Sugahara T, Korogi Y, Kochi M, Ikushima I, Shigematu Y, Hirai T, et al. Usefulness of diffusionweighted MRI with echo-planar technique in the evaluation of cellularity in gliomas. $\mathrm{J}$ Magn Reson Imaging JMRI. 1999 Jan; 9(1):53-60. [PubMed: 10030650]

9. Gauvain KM, McKinstry RC, Mukherjee P, Perry A, Neil JJ, Kaufman BA, et al. Evaluating pediatric brain tumor cellularity with diffusion-tensor imaging. AJR Am J Roentgenol. 2001 Aug; 177(2):449-54. [PubMed: 11461881]

10. Sun Y-S, Zhang X-P, Tang L, Ji J-F, Gu J, Cai Y, et al. Locally advanced rectal carcinoma treated with preoperative chemotherapy and radiation therapy: preliminary analysis of diffusion-weighted MR imaging for early detection of tumor histopathologic downstaging. Radiology. 2010 Jan; 254(1):170-8. [PubMed: 20019139]

11. Joye I, Deroose CM, Vandecaveye V, Haustermans K. The role of diffusion-weighted MRI and (18)F-FDG PET/CT in the prediction of pathologic complete response after radiochemotherapy for 
rectal cancer: a systematic review. Radiother Oncol J Eur Soc Ther Radiol Oncol. 2014 Nov; 113(2):158-65.

12. Cho SH, Kim GC, Jang Y-J, Ryeom H, Kim HJ, Shin K-M, et al. Locally advanced rectal cancer: post-chemoradiotherapy ADC histogram analysis for predicting a complete response. Acta Radiol Stockh Swed 1987. 2015 Sep; 56(9):1042-50.

13. Lambrecht M, Vandecaveye V, De Keyzer F, Roels S, Penninckx F, Van Cutsem E, et al. Value of diffusion-weighted magnetic resonance imaging for prediction and early assessment of response to neoadjuvant radiochemotherapy in rectal cancer: preliminary results. Int J Radiat Oncol Biol Phys. 2012 Feb 1; 82(2):863-70. [PubMed: 21398048]

14. Lambrecht M, Deroose C, Roels S, Vandecaveye V, Penninckx F, Sagaert X, et al. The use of FDG$\mathrm{PET} / \mathrm{CT}$ and diffusion-weighted magnetic resonance imaging for response prediction before, during and after preoperative chemoradiotherapy for rectal cancer. Acta Oncol Stockh Swed. 2010 Oct; 49(7):956-63.

15. van Rossum PSN, van Lier ALHMW, van Vulpen M, Reerink O, Lagendijk JJW, Lin SH, et al. Diffusion-weighted magnetic resonance imaging for the prediction of pathologic response to neoadjuvant chemoradiotherapy in esophageal cancer. Radiother Oncol J Eur Soc Ther Radiol Oncol. 2015 May; 115(2):163-70.

16. Zhu A, Lee D, Shim H. Metabolic positron emission tomography imaging in cancer detection and therapy response. Semin Oncol. 2011 Feb; 38(1):55-69. [PubMed: 21362516]

17. Chen Y, Pan X, Tong L, Shi Y, Chen T. Can ${ }^{18}$ F-fluorodeoxyglucose positron emission tomography predict responses to neoadjuvant therapy in oesophageal cancer patients? A metaanalysis. Nucl Med Commun. 2011 Nov; 32(11):1005-10. [PubMed: 21886014]

18. Kwee RM. Prediction of tumor response to neoadjuvant therapy in patients with esophageal cancer with use of 18F FDG PET: a systematic review. Radiology. 2010 Mar; 254(3):707-17. [PubMed: 20177086]

19. Mandard AM, Dalibard F, Mandard JC, Marnay J, Henry-Amar M, Petiot JF, et al. Pathologic assessment of tumor regression after preoperative chemoradiotherapy of esophageal carcinoma. Clinicopathologic correlations. Cancer. 1994 Jun 1; 73(11):2680-6. [PubMed: 8194005]

20. Li Q-W, Qiu B, Wang B, Wang D-L, Yin S-H, Yang H, et al. Prediction of pathologic responders to neoadjuvant chemoradiotherapy by diffusion-weighted magnetic resonance imaging in locally advanced esophageal squamous cell carcinoma: a prospective study. Dis Esophagus Off J Int Soc Dis Esophagus. 2017 Sep 27.

21. Elimova E, Wang X, Etchebehere E, Shiozaki H, Shimodaira Y, Wadhwa R, et al. 18fluorodeoxyglucose positron emission computed tomography as predictive of response after chemoradiation in oesophageal cancer patients. Eur J Cancer Oxf Engl 1990. 2015 Nov; 51(17): 2545-52. 
Early quantitative change in tumor apparent diffusion coefficients from diffusionweighted MR imaging discriminates complete pathologic response from nonresponse after chemoradiation in esophageal cancer. Early change in total lesion glycolysis by FDG-PET/CT also discriminates pathologic response from nonresponse after chemoradiation in esophageal cancer. Early prediction of pathologic response to chemoradiation in esophageal cancer is feasible using quantitative ADC and FDG$\mathrm{PET} / \mathrm{CT}$ and could enable patient selection for treatment de-escalation. 

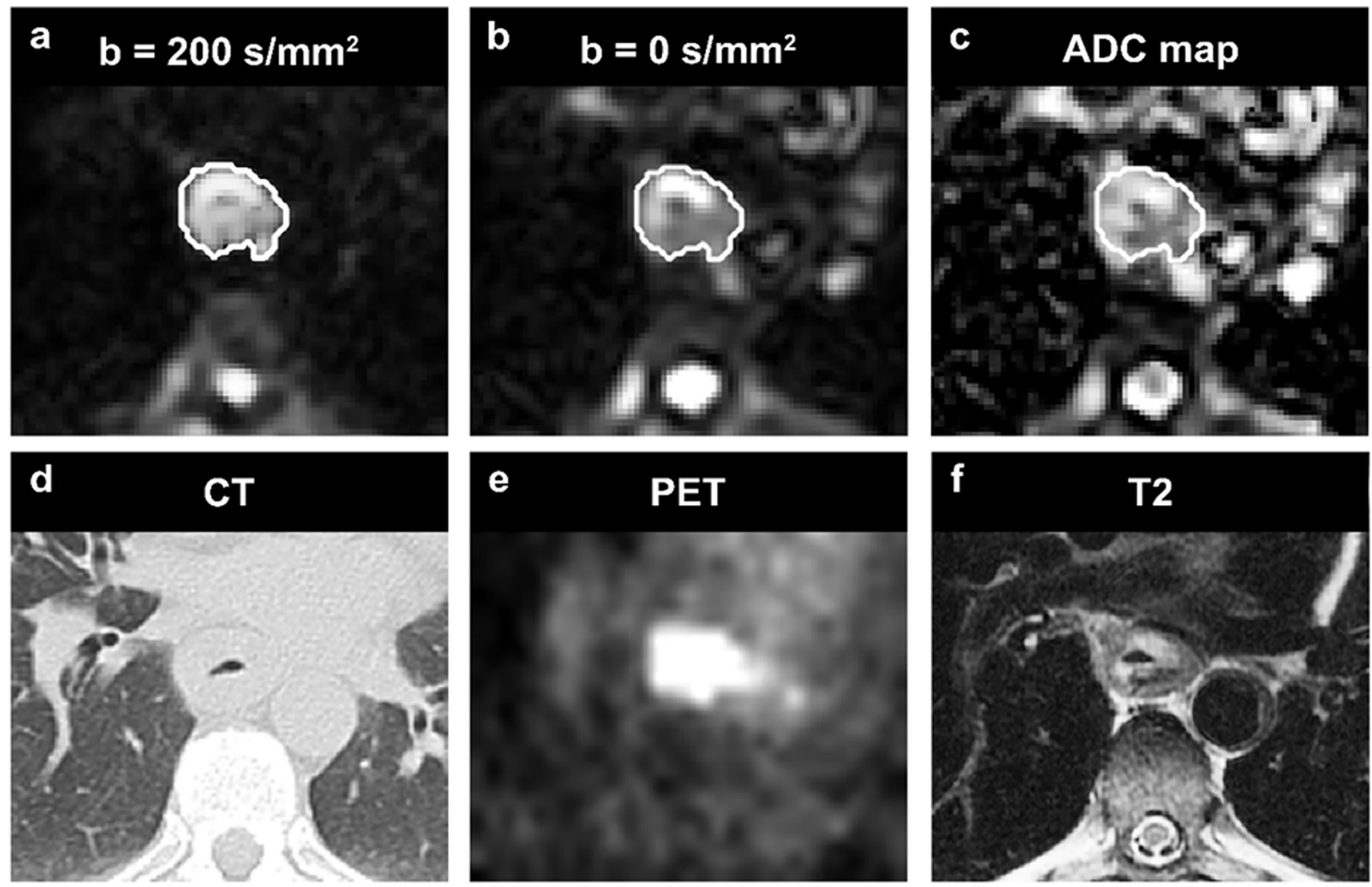

Figure 1.

Images and parameter maps across imaging modalities on the same axial slice of tumor: diffusion images b200 (a) and b0 (b), ADC map (c), CT (d), FDG-PET (e), and T2 weighted (f). 
a
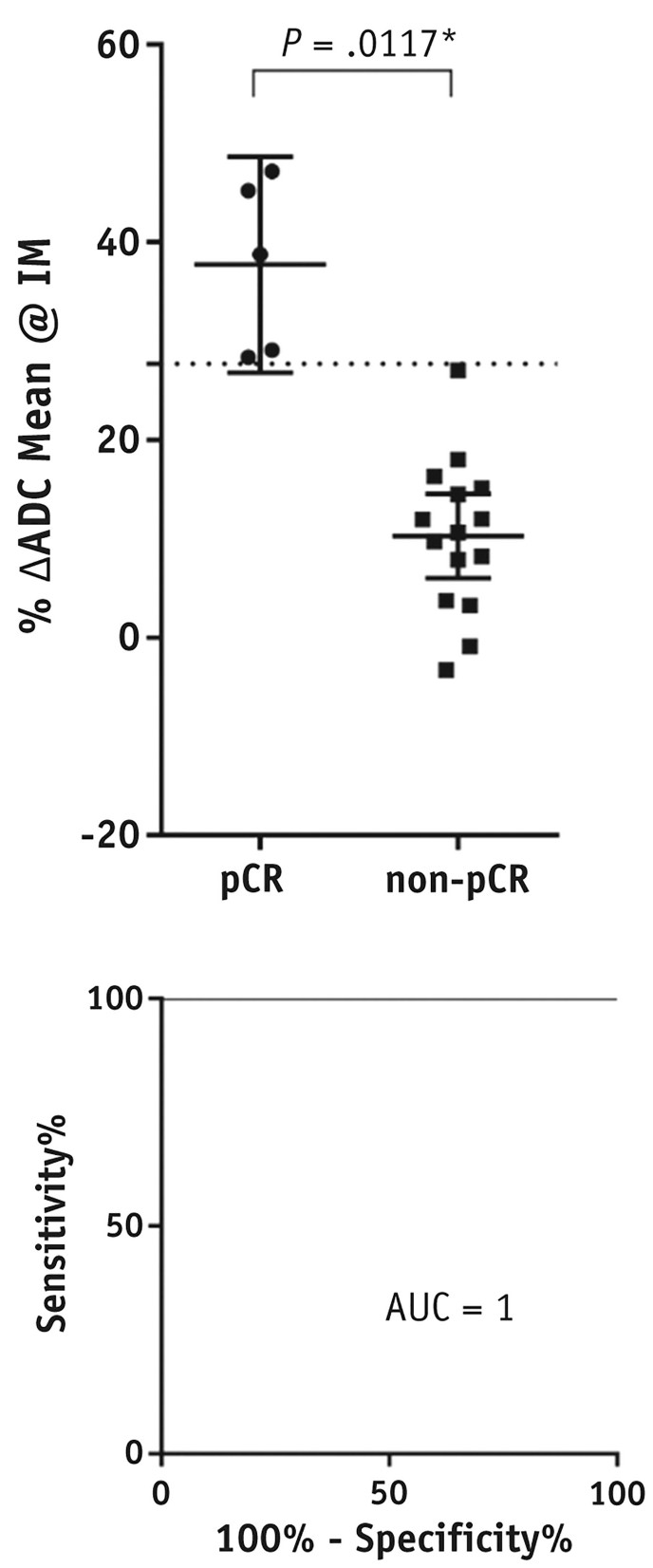

b
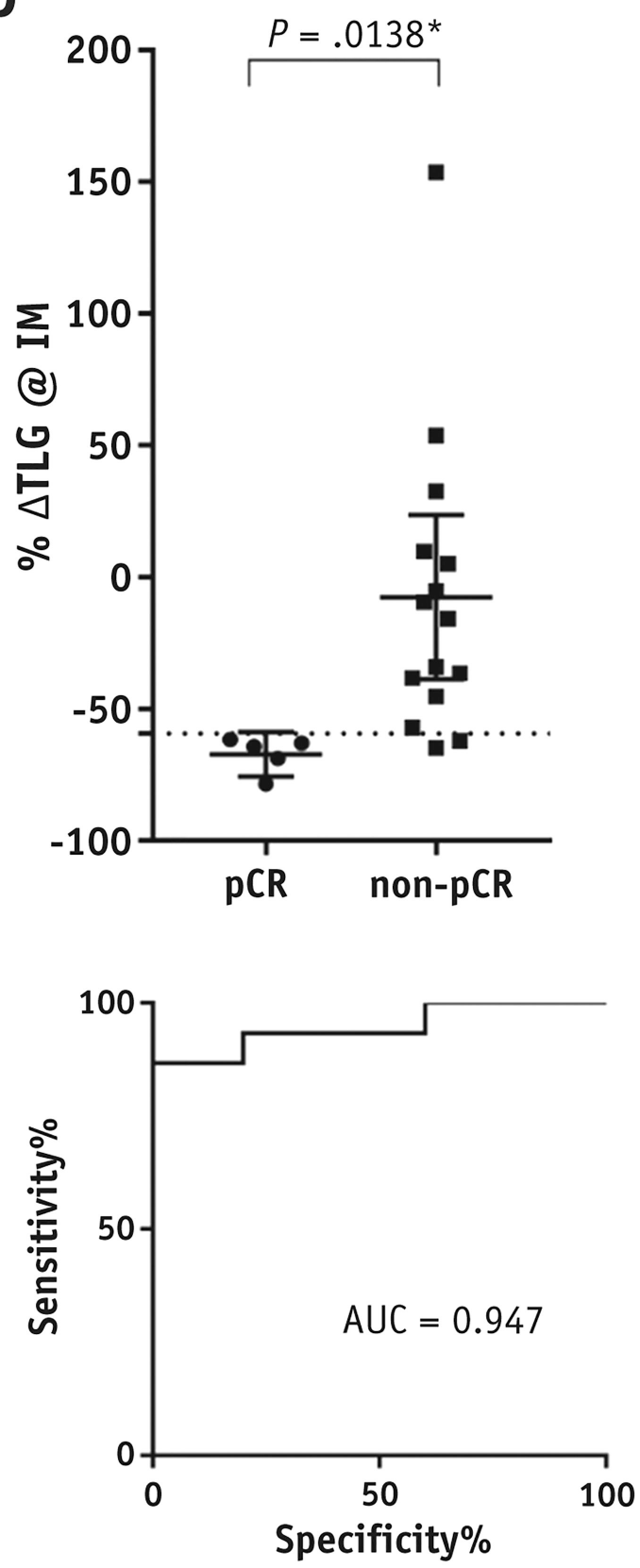

Figure 2.

Comparison of biomarker distributions between pCR and non-pCR for (a) $\triangle \mathrm{ADC}$ mean and (b) $\triangle$ TLG. In the dot plots, $95 \%$ confidence intervals are shown as well as solid horizontal bars indicating average biomarker value for each response group. Dotted lines show cutoffs optimized by Youden's index. Below each plot is an ROC curve showing the classification performance of its respective biomarker. 


\section{Table 1}

Patient Population Characteristics

\begin{tabular}{|c|c|}
\hline Characteristic & $\mathbf{N}(\%)$ \\
\hline \multicolumn{2}{|l|}{ Gender } \\
\hline Male & $20(100.0)$ \\
\hline Female & $0(0.0)$ \\
\hline Age (years) & $62.1+/-8.0 *$ \\
\hline \multicolumn{2}{|l|}{ Histological Tumor Type } \\
\hline Adenocarcinoma & $17(85.0)$ \\
\hline Squamous cell carcinoma & $3(15.0)$ \\
\hline \multicolumn{2}{|l|}{ Histological Tumor grade } \\
\hline Well Differentiated & $0(0.0)$ \\
\hline Moderately Differentiated & $9(55.0)$ \\
\hline Poorly Differentiated & $11(45.0)$ \\
\hline \multicolumn{2}{|l|}{ Clinical Stage } \\
\hline IIa & $1(5.0)$ \\
\hline IIb & $5(25.0)$ \\
\hline IIIa & $12(60.0)$ \\
\hline IIIb & $2(10.0)$ \\
\hline \multicolumn{2}{|l|}{ Tumor Location } \\
\hline Proximal third & $0(0.0)$ \\
\hline Middle third & $1(5.0)$ \\
\hline Distal third & $17(85.0)$ \\
\hline Gastro-esophageal junction & $2(10.0)$ \\
\hline \multicolumn{2}{|l|}{ Histopathologic T-stage } \\
\hline урт0 & $5(25.0)$ \\
\hline урT1a & $2(10.0)$ \\
\hline урт1b & $2(10.0)$ \\
\hline урT2 & $3(15.0)$ \\
\hline урT3 & $8(40.0)$ \\
\hline \multicolumn{2}{|l|}{ Histopathologic $N$-stage } \\
\hline ypNo & $14(70.0)$ \\
\hline ypN1 & $4(20.0)$ \\
\hline ypN2 & $2(10.0)$ \\
\hline ypN3 & $0(0.0)$ \\
\hline \multicolumn{2}{|c|}{ Histopathologic Tumor Regression Grade } \\
\hline TRG 1 & $5(25.0)$ \\
\hline TRG 2 & $9(19.0)$ \\
\hline
\end{tabular}




$\begin{array}{ll}\text { Characteristic } & \mathrm{N}(\%)\end{array}$

$\begin{array}{ll}\text { TRG } 3-5 & 6(30.0)\end{array}$

For patient age, the format is mean $+/-$ standard deviation. 


\section{Table 2}

Comparing Relative Changes @ IM of ADC Summary Measures between pCR and nonpCR using MannWhitney Test

\begin{tabular}{|lllll|}
\hline Feature & $\begin{array}{l}\text { Bonferroni } \\
\text { Adjusted } \\
\text { p-value }\end{array}$ & $\begin{array}{l}\text { Histopathologic } \\
\text { Response }\end{array}$ & $\begin{array}{l}\text { Relative \% Change } \\
\text { (Mean +/- STD) }\end{array}$ & AUC \\
\hline ADC Mean & 0.011 & $\begin{array}{l}\text { pCR/TRG1 } \\
\text { non-pCR/TRG2+ }\end{array}$ & $\begin{array}{l}37.73+/-8.77 \\
9.41+/-7.53\end{array}$ & 1.000 \\
\hline ADC 25 ${ }^{\text {th }}$ Percentile & 0.011 & pCR/TRG1 & $47.12+/-11.18$ & 1.000 \\
\hline & & non-pCR/TRG2+ & $10.37+/-8.43$ & \\
ADC 10 ${ }^{\text {th }}$ Percentile & 0.011 & pCR/TRG1 & $53.23+/-20.46$ & 1.000 \\
\hline ADC Median & 0.015 & non-pCR/TRG2+ & $10.17+/-12.50$ & \\
\hline & & non-pCR/TRG2+ & $10.65+/-7.42$ & 0.987 \\
ADC 75 ${ }^{\text {th }}$ Percentile & 0.021 & pCR/TRG1 & $35.73+/-12.11$ & 0.973 \\
\hline
\end{tabular}


Table 3

Comparing Baseline ADC Summary Measures between pCR and non-pCR using Mann-Whitney Test

\begin{tabular}{|c|c|c|c|c|}
\hline Summary Measure & $\begin{array}{l}\text { Bonferroni } \\
\text { Adjusted } \\
\text { p-value }\end{array}$ & $\begin{array}{l}\text { Histopathologic } \\
\text { Response }\end{array}$ & $\mathrm{ADC}$ in $\times 10^{-3} \mathrm{~mm}^{2} / \mathrm{s}$ & AUC \\
\hline \multirow{2}{*}{ Volume ADC Mean } & \multirow{2}{*}{0.180} & pCR/TRG1 & $2.22+/-0.17$ & \multirow{2}{*}{0.867} \\
\hline & & non-pCR/TRG2+ & $2.62+/-0.34$ & \\
\hline \multirow{2}{*}{ Volume ADC $25^{\text {th }}$ Percentile } & \multirow{2}{*}{0.227} & pCR/TRG1 & $1.82+/-0.15$ & \multirow{2}{*}{0.853} \\
\hline & & non-pCR/TRG2+ & $2.23+/-0.34$ & \\
\hline \multirow{2}{*}{ Volume ADC Median } & \multirow{2}{*}{0.287} & pCR/TRG1 & $2.18+/-0.16$ & \multirow{2}{*}{0.840} \\
\hline & & non-pCR/TRG2+ & $2.59+/-0.38$ & \\
\hline \multirow{2}{*}{ Volume ADC $75^{\text {th }}$ Percentile } & \multirow{2}{*}{0.357} & pCR/TRG1 & $2.57+/-0.21$ & \multirow{2}{*}{0.827} \\
\hline & & non-pCR/TRG2+ & $3.00+/-0.38$ & \\
\hline
\end{tabular}




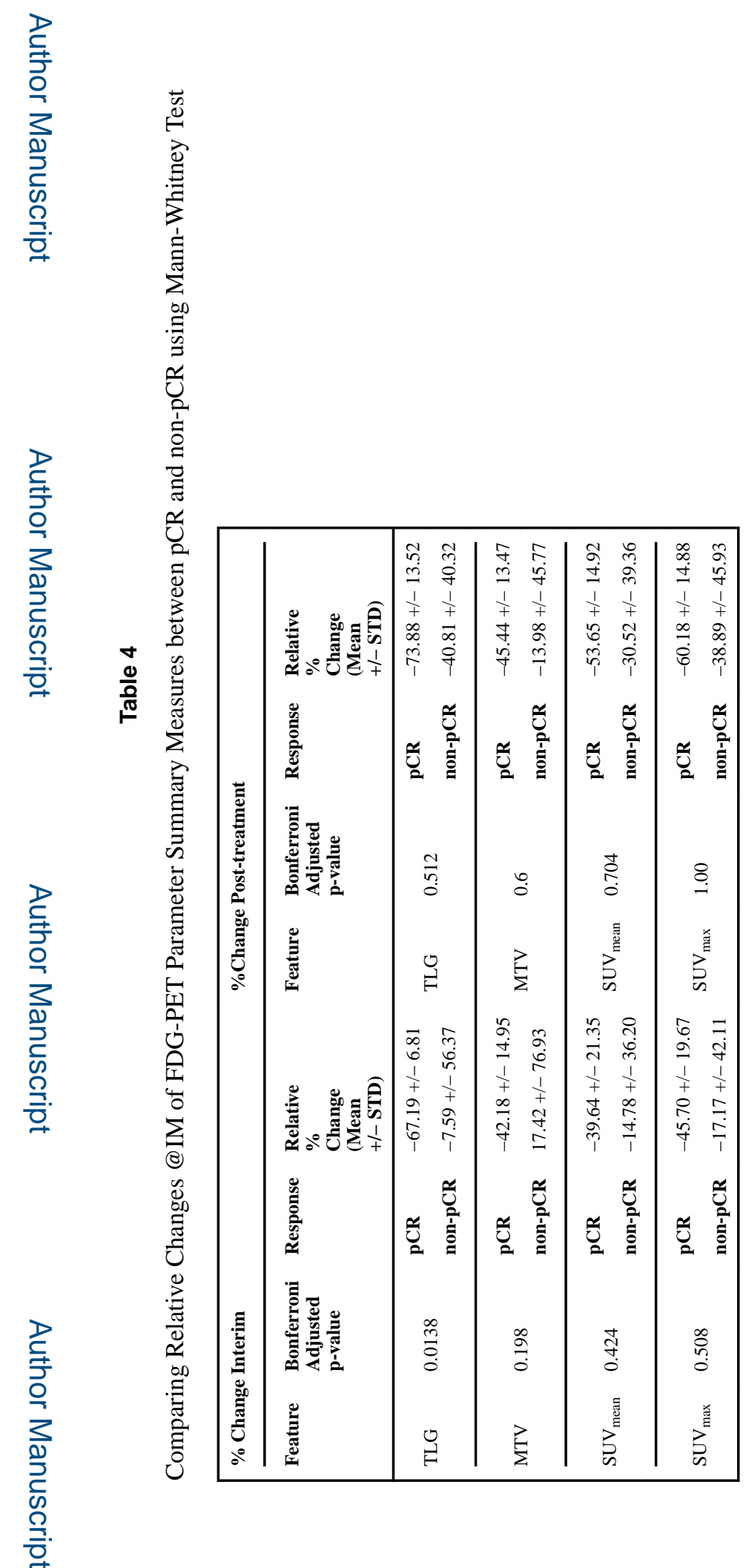

Int J Radiat Oncol Biol Phys. Author manuscript; available in PMC 2019 November 15. 